\title{
Implementasi Metode Ishihara pada Tes Buta Warna (Colour Deficiency) di Klinik Amanda-Anyer
}

\author{
Fenny Nur Efrianty ${ }^{1}$, Harsiti ${ }^{2}$, M. Thoha Nurhadiyan ${ }^{3}$ \\ ${ }^{1,3}$ Program Studi Teknik Informatika Fakultas Teknologi Informasi Universitas Serang Raya \\ ${ }^{2}$ Program Studi Sistem Informas Fakultas Teknologi Informasi Universitas Serang Raya \\ Jalan Raya Serang, Cilegon KM.5 Taman Drangong Serang, Drangong, Serang, \\ ${ }^{1}$ fennynurefrianty08@gmail.com, \\ 2harsiti@yahoo.com, \\ 3 thoha.nurhadiyan@gmail.com
}

\begin{abstract}
Abstrak - Buta Warna adalah suatu keadaan dimana seseorang tidak dapat membedakan warna tertentu yang bisa dibedakan oleh orang dengan mata normal. Seseorang yang menderita buta warna dapat disebabkan oleh kelainan sejak lahir atau akibat penggunaan obat-obatan yang berlebihan. Buta warna umumnya diderita oleh laki-laki, sedangkan wanita hanyalah sebagai gen pembawa atau resesif. Metode Ishihara adalah metode yang digunakan untuk mendeteksi gangguan persepsi warna, berupa tabel warna khusus berupa lembaran pseudoisokromatik (plate) yang disusun oleh titik-titik dengan kepadatan warna berbeda yang dapat dilihat dengan mata normal, tapi tidak bisa dilihat oleh mata yang mengalami defisiensi sebagian warna. Implementasi Metode Ishihara Pada Tes Buta Warna (Colour Deficiency). Penelitian ini dilakukan d Klinik Amanda-Anyer, salah satu klinik yang mengimplementasikan aplikasi tes buta warna sehingga klinik tidak memperlukan lagi buku-buku ishihara untuk proses pengetesan tes buta warna dan dapat melakukan tes buta warna dengan efektif tanpa rekayasa dan hasil yang sesuai, tepat dan cepat. Aplikasi ini dibangun dan dirancang dengan menggunakan metode watterfall dan diagram UML (Unified Modeling Language). Bahasa pemrograman yang digunakan dalam pengembangan aplikasi ini adalah Vb.Net10, dengan database SQLServer2008. Berdasarkan hasil dari pengujian dan penilaian sistem yang telah dilakukan, dapat disimpulkan bahwa Implementasi Metode Ishihara pada Tes Buta Warna (Colour Deficiency) dapat membantu Pihak Klinik Amanda-Anyer dalam melakukan proses pengetesan buta warna bagi masyarakat yang membutuhkan keterangan hasil buta warna dengan hasil yang cepat dan akurat.
\end{abstract}

Kata Kunci : Metode Ishihara, Tes Buta Warna (Colour Deficiency), klinik Amanda-Anyer.

\section{PENDAHULUAN}

Klinik Amanda merupakan salah satu Klinik yang berada di Daerah Anyer. Klinik ini melayani berbagai macam pelayanan Kesehatan, seperti Imunisasi Bayi dan Balita,Pelayanan KIA/KB, Persalinan (24Jam), Tes Buta Warna, Imunisasi Ibu Hamil, Pelayanan Rawat Inap, dll.

Salah satu bentuk pelayanan yang di sediakan pada Klinik tersebut adalah Tes Buta Warna. Akan tetapi, pada pelayanan pemeriksaan Tes Buta Warna tersendiri masih menggunakan buku Ishihara (metode buku yang di gunakan khusus untuk Tes Buta Warna). Sedangkan untuk pelayanan ini juga masih banyak yang membutuhkan, seperti anak SMA/SMP yang membutuhkan cek Buta Warna untuk syarat melanjutkan kejenjang sekolah yang lebih tinggi, begitupun para pekerja juga membutuhkan cek buta warna untuk alasan tertentu.

Adapun yang di maksud dari Buta Warna adalah suatu keadaan dimana seseorang tidak dapat membedakan warna tertentu yang bisa dibedakan oleh orang dengan mata normal. Seseorang yang menderita buta warna dapat disebabkan oleh kelainan sejak lahir atau akibat penggunaan obatobatan yang berlebihan. Buta warna umumnya diderita oleh laki-laki, sedangkan wanita hanyalah sebagai gen pembawa atau resesif.

Salah satu metode tes buta warna adalah Metode Ishihara. Metode ini dilakukan dengan cara memperlihatkan gambar pseudo-isochromatic yang diantara warna-warnanya terdapat angka-angka yang perlu ditebak. Proses dengan metode Ishihara ini biasanya dilakukan dengan cara manual, yaitu 
dengan cara memperlihatkan lembaran-lembaran gambar pseudo-isochromatic pada pasien oleh dokter yang kemudian pasien akan menjawab sesuai apa yang dilihat angka didalamnya.

Sedangkan gambar didalam Buku Ishihara tersendiri berisi cetakan gambar pseudoisochromatic akan mengalami perubahan warna karena bertambahnya usia buku, warna yang ada pada pseudo-isochromatic akan pudar atau kusam jika terlalu lama disimpan, atau terkena cahaya, kekusaman warna akan merubah keaslian plat untuk alat uji sehingga akan mempengaruhi keakuratan hasil tes. Selain pemeliharaan buku Ishihara yang sulit, harga dari buku test tersebut sangat mahal.

Proses Tes Buta Warna yang dilakukan secara manual akan mendapatkan hasil tes yang kemudian akan hanya dicatat pada suatu lembar form tertentu. Untuk pengarsipan bagi lembaga yang menyimpan data hasil tes tidak menyimpan dengan benar, maka lembar form hasil tes pasien yang melakukan tes buta warna akan hilang.

Selain itu, terkadang pada pemeriksaan tes buta warna juga mengalami adanya rekayasa hasil tes buta warna itu sendiri, yaitu seperti, yang seharusnya seorang pasien tersebut mengalami buta warna akan tetapi, berhubung pasien adalah kerabat dokter, maka pasien meminta dokternya (kerabatnya) melakukan manipulasi data yang dimana hasil yang diminta ialah hasil normal, atau kejadian lainnya.

Berdasarkan latar belakang yang telah diuraikan maka penelitian ini akan mengembangkan sebuah Aplikasi Tes Buta Warna, yang berfungsi sebagai alat bantu bagi Klinik Amanda dalam masalah Tes Buta Warna secara efisien terutama pada penyimpanan hasil tes pasien dan penumpukkan buku-buku yang sudah tidak terpakai. Tes akan dilakukan menggunakan layar komputer sebagai pengganti buku yang berisi gambar-gambar metode Ishihara dan diolah kedalam sebuah komputer. Selain itu juga hasil tes para pasien akan disimpan dalam sebuah database yang nantinya akan berfungsi sebagai rekapitulasi data pasien pertahun atau pertanggal sehingga petugas kesehatan dapat langsung mencetak laporan melalui cetak printer. Dan juga melakukkan antisipasi adanya kerjasama hasil antara dokter dan pasien. Diharapkan dalam penerapan sistem ini dapat membantu pelayanan kesehatan untuk tes buta warna sehingga mempelancar kegiatan di Klinik tersebut.

\section{Tujuan Penelitian}

Adapun Tujuan dilaksankan penelitian,diantaranya sebagai berikut :

1. Agar tidak terjadi penumpukkan buku ishihara.

2. Mempermudah pasien dalam melakukan tes buta warna
3. Mempercepat dan mempermudah dalam proses hasil pemeriksaan.

4. Agar tidak terjadi rekayasa hasil tes.

5. Mempermudah klinik dalam merekapitulasi laporan.

\section{Tinjauan Pustaka dan Landasan Teori \\ a. Buta Warna}

Buta warna adalah suatu kelainan yang disebabkan ketidakmampuan sel-sel kerucut mata untuk menangkap suatu spektrum warna tertentu yang disebabkan oleh faktor genetis. Buta warna merupakan kelainan genetika yang diturunkan dari orang tua kepada anaknya, kelainan ini sering juga disebut sex linked, karena kelainan ini dibawa oleh Kromosom X. Artinya kromosom Y tidak membawa faktor buta warna. Hal inilah yang membedakan antara penderita buta warna pada laki-laki dan perempuan. Seorang perempuan terdapat istilah 'pembawa sifat' hal ini dapat menunjukkan ada satu kromosom X yang membawa sifat buta warna. Perempuan dengan pembawa sifat, secara fisik tidak mengalami kelainan buta warna sebagaimana wanita normal pada uumnya, tetapi wanita dengan pembawa sifat berpotensi menurunkan faktor buta warna kepada anaknya kelak. Apabila pada kedua kromosom X mengandung faktor buta warna maka seorang wanita tersebut menderita buta warna. Saraf sel pada retina terdiri atas sel batang yang peka terhadap hitam dan putih, serta sel kerucut yang peka terhadap warna lainnya. Buta warna terjadi ketika syaraf reseptor cahaya di retina mengalami perubahan, terutama sel kerucut.

Sedangkan menurut Mila Jurmalis (2014), Buta warna sebenarnya adalah ketidakmampuan seseorang untuk membedakan warna tertentu yang disebabkan oleh gangguan pada sel krucut (cone) di retina mata. Orang tersebut biasanya tidak buta pada semua warna melainkan warnawarna tertentu saja. Buta warna umumnya diturunkan ada juga yang didapat misalnya pada penyakit di retina mata.

\section{b. Metode Ishihara}

Metode Ishihara yaitu metode yang dapat dipakai untuk menentukan dengan cepat suatu kelainan buta warna didasarkan pada penggunaan kartu bertitik-titik yang mempunyai bermacam-macam warna.

Gambar 2.1 Contoh Gambar Tes Buta Warna dengan Metode Ishihara

Sumber:http://jazma101.multiply.com

September 2017

Menurut Ratri Widianingsih dkk (2010), Metode Ishihara ini di kembangkan oleh Dr. Shinobu Ishihara. pertama kali dipublikasi pada 
tahun 1917 dijepang dan terus digunakan di seluruh dunia, sampai sekarang. Tes Buta Warna metode Ishihara terdiri dari lembaran yang didalamnya terdapat titik-titik warna.

Proses tes buta warna dengan metode ishihara ini umumnya dilakukan secara manual, yaitu dengan memperlihatkan lembar-lembar gambar oleh seorang petugas tes buta warna dan peserta tes diminta menyebuatkan angka-angka yang terlihat pada gambar. Dari beberapa gambar yang diperlihatkan dan jawaban yang diberikan oleh peserta tes butawarna, maka petugas akan menyimpulkan apakah peserta tes mengalami buta warna total, atau normal.

Peran komputer dalam proses tes ini adalah menggunakan layar komputer pengganti kertaskertas berisi gambar dari metode Ishihara, yaitu lembaran yang di dalamnya terdapat titik-titik dengan berbagai warna dan ukuran. Titik berwarna tersebut disusun sehingga membentuk lingkaran. Warna titik itu dibuat sedemikian rupa sehingga orang buta warna tidak akan melihat perbedaan warna seperti yang dilihat orang normal. Hasil tes akan disimpan dalam database, sehingga petugas kesehatan dapat mengecek data yang lalu serta menghasilkan laporan yang dapat langsung dicetak melalui printer.

Menurut Randy Viyata dkk (2014), Tes buta warna Ishihara terdiri dari lembaran yang di dalamnya terdapat titik-titik dengan berbagai warna dan ukuran. Titik-titik berwarna tersebut disusun sehingga membentuk lingkaran yang didalamnya terdapat titik-titik dengan pola membentuk angka maupun.Warna titik-titik itu dibuat sedemikian rupa sehingga orang buta warna tidak akan berhasil melihat angka maupun garis yang ada. Di ruangan dengan penerangan yang cukup, pasien diminta melihat plate dan diminta untuk mengidentifikasi atau menyebutkan angka yang terdapat pada titiktitik warna berbentuk lingkaran tidak lebih dari 10 detik. Pada orang normal, di dalam lingkaran akan tampak angka tertentu. Tetapi pada orang buta warna, yang tampak dalam lingkaran tersebut akan berbeda seperti yang dilihat oleh orang normal atau ia tidak bisa melihat angka yang ada.

\section{c. Tahapan Dalam Pemeriksaan Tes Buta} Warna

Tahapan yang terdapat dalam pemeriksaan Tes Buta Warna menggunakan Metode Ishihara, Ratri Widianingsih dkk (2010), yaitu :

1. Menggunakan buku Ishihara 14 Plate.

2. Yang Perlu Diperhatikan:

- Cahaya pada ruang pemeriksaan harus cukup
- Waktu pengamatan untuk menjawab setiap gambarnya selama 5 detik.

3. Pada tes pembacaan buku Ishihara dapat disimpulkan hasil diantaranya :

- Buta Warna

- Tidak Buta Warna

\section{d. Klasifikasi Tes Buta Warna atau Tidak Buta} Warna

Buta warna dapat dites melalui metode Ishihara, dimana lingkaran-lingkaran berwarna yang beberapa diantaranya terdapat tulisan tertentu itu membentuk sebuah metode yang memudahkan dalam mendiagnosa pasien apakah dapat dilihat atau tidak dapat dilihat. Masalah yang dirasakan oleh penderita buta warna adalah kesulitan mengenali warna tertentu atau tidak bisa melihat warna tertentu.

Terdapat 14 macam Plate dalam tes buta warna Ishihara, yaitu :
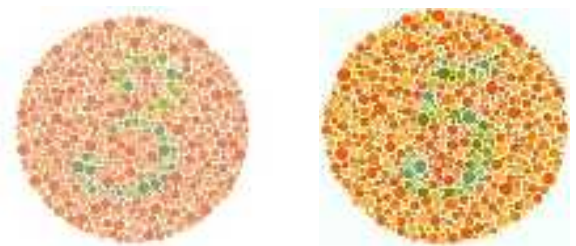

Gambar 1. Plate No. 1 dan Plate No.2

Pada Plate No. 1 dan Plate No. 2 akan terlihat angka 3 dan angka 5 apabila dilihat oleh orang yang normal. Bagi orang yang tidak normal maka tidak akan terlihat angka berapun pada gambar atau akan menjawab angka 8 pada Plate No. 1.
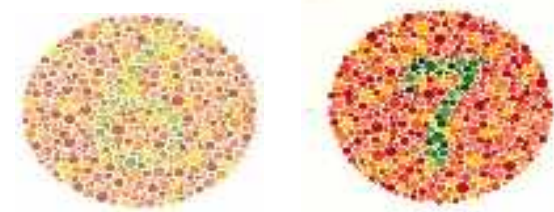

Gambar 2. Plate No. 3 dan Plate No.4
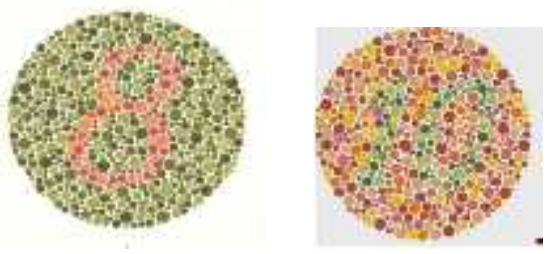

Gambar 3. Plate 5 dan Plate 6
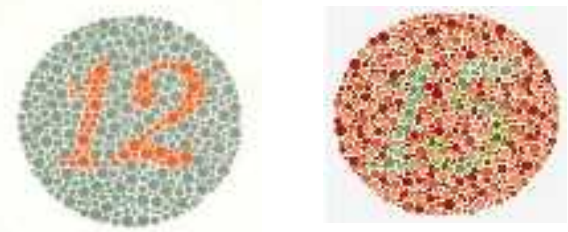

Gambar 4. Plate No. 7 dan Plate 8
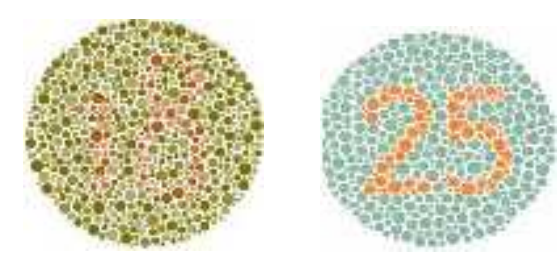


\section{Gambar 5. Plate 9 dan Plate 10}
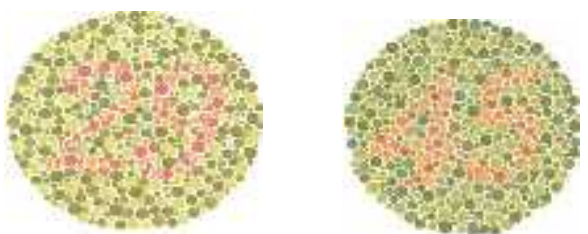

Gambar 6. Plate No 11 dan Plate No. 12
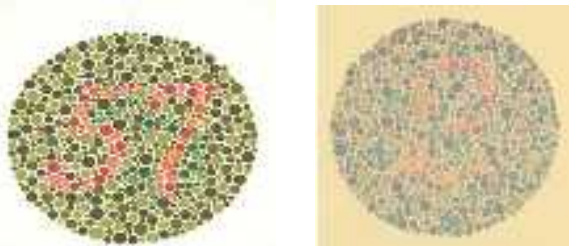

Gambar 7.Plate No. 13 dan Plate 14

Tabel 2.1 Pengambilan Kesimpulan menurut Ratri W. Tes Buta Warna

\begin{tabular}{|l|l|}
\hline Kesimpulan Tes & $\begin{array}{l}\text { Pengambilan } \\
\text { Kesimpulan }\end{array}$ \\
\hline Buta Warna & $\begin{array}{l}\text { Jika gambar dijawab } \\
\text { salah atau } \\
\text { mengabaikan gambar } \\
\text { lainnya. }\end{array}$ \\
\hline Tidak Buta Warna & $\begin{array}{l}\text { Dapat menjawab } \\
\text { angka yang ada }>=7 \\
\text { angka }\end{array}$ \\
\hline
\end{tabular}

e. Algoritma Tes Buta Warna

Aplikasi tes buta warna Ishihara dalam penelitian ini ditampilkan 14 Plate saja yang merupakan gambar-gambar utama dari tes buta warna Ishihara. Dengan 14 Plate ini sudah dapat disimpulkan kondisi orang yang di tes apakah mengalami buta warna atau tidak buta warna. Dalam proses menampilkan 14 Plate gambar tes buta warna Ishihara ini dapat dilakukan dengan urut dari awal sampai akhir atau dari urutan akhir ke awal.

\section{METODOLOGI PENELITIAN}

Penelitian ini diawali dengan tahap perencanaan pengembangan sistem dengan melakukan survey terhadap objek penelitian. Selanjutnya dilakukan proses analisa kebutuhan sistem untuk kemudian dibuatkan fungsionalitas sistem untuk masing-masing entitas yang terlibat. Tahap perancangan dilakukan setelah melakukan deskripsi fungsi sistem, kemudian dibuatkan diagram pendukung perancangan sistem, meliputi, diagram use case, class diagram, entitas relationship diagram, sequence diagram, dan Activity diagram. Kegiatan selanjutnya adalah membuat waterfall sistem menggunakan bahasa pemograman visual basic dan terakhir menulis laporan penelitian.

\section{HASIL DAN PEMBAHASAN}

1. Perancangan Sistem Menggunakan UML

\section{a. Usecase Diagram Aplikasi Tes Buta} Warna

Diagram use case digunakan untuk memodelkan fungsional sistem yang digunakan oleh pengguna sistem. Berikut ini adalah diagram use case untuk aplikasi Tes Buta Warna pada Klinik Amanda-Anyer.

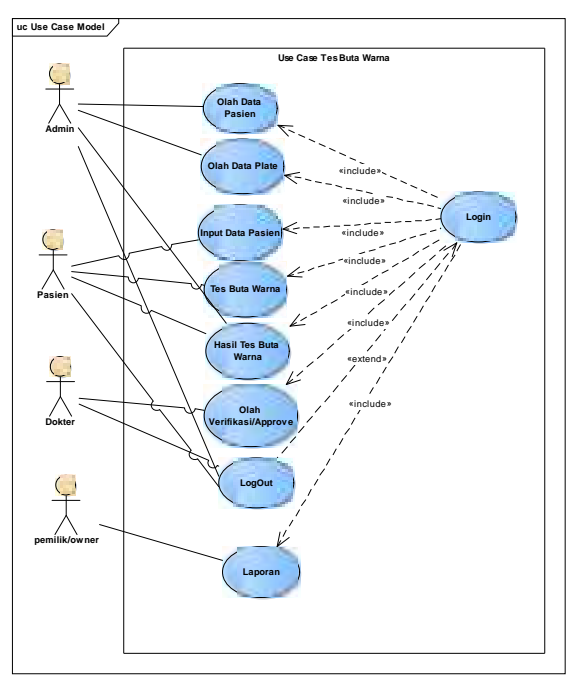

Gambar 8. Use Case Diagram Implementasi metode ishihara pada tes buta warna(colour deficiency)

\section{b. Activity Diagram Aplikasi Tes Buta Warna}

Activity diagram adalah diagram yang menggambarkan sifat dinamis secara alamiah sebuah sistem ke dalam bentuk model aliran dan control dari aktivitas lainnya.

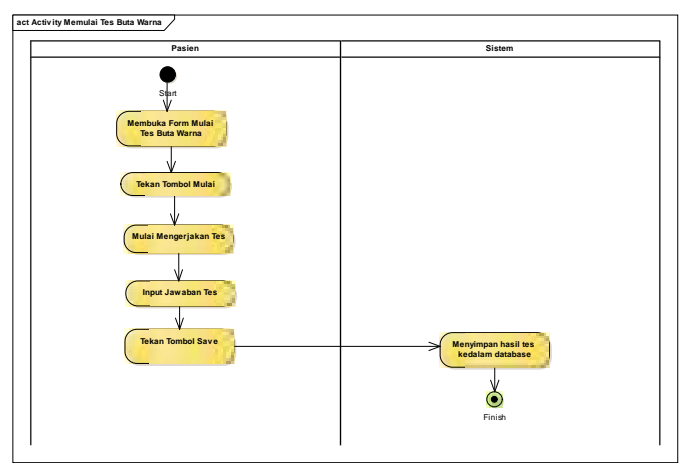

Gambar 9. Activity Diagram Mulai Tes Buta Warna 
c. Sequence Diagram Aplikasi Tes Buta Warna

Sequence diagram merupakan diagram interaksi yang menekankan pada urutan waktu terjadinya pesan.

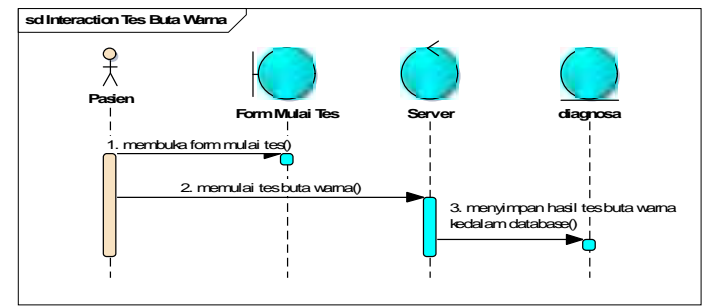

Gambar 10. Sequence Diagram Tes Buta Warna

d. Class Diagram Aplikasi Tes Buta Warna

Class diagram adalah sebuah class menjelaskan hubungan antar class dalam sebuah sistem yang sedang dibuat dan bagaimana caranya agar mereka saling berkolaborasi untuk mencapai sebuah tujuan. Berikut ini merupakan class diagram untuk proses penerapan Implementasi Metode ishihara pada tes buta warna (colour deficiency) di klinik Amanda-anyer.

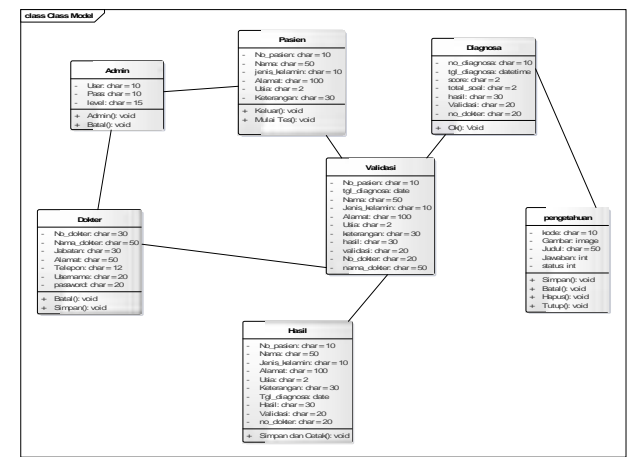

Gambar 11. Diagram Class

\section{e.ERD (Entity Relationship Diagram)}

Entity Relationship Diagram (ERD) adalah sekumpulan cara atau peralatan untuk mendeskripsikan data-data atau objek-objek yang dibuat berdasarkan dan berasal dari dunia nyata yang disebut entitas (entity) serta hubungan (relationship) antar entitas-entitas tersebut dengan menggunakan beberapa notasi. Berikut ini merupakan ERD untuk proses penerapan Implementasi Metode ishihara pada tes buta warna (colour deficiency) di klinik Amanda-anyer

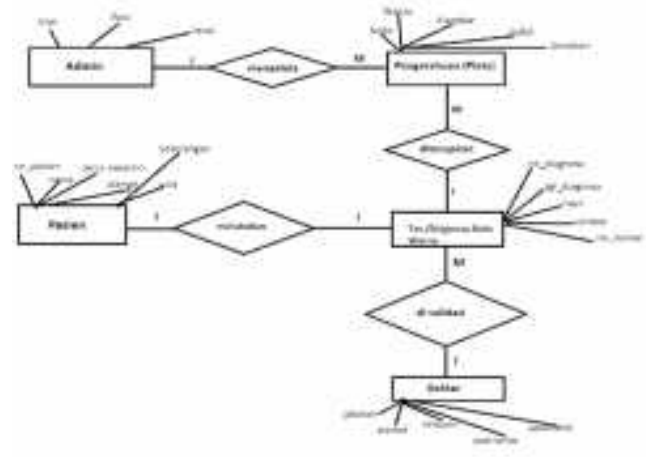

Gambar 12. Entity Relationship Diagram (ERD)

\section{Aplikasi Tes Buta Warna}

Aplikasi tes buta warna dirancang dan diterapkan dalam di Klinik Amanda-Anyer. Berikut ini tampilam menu dalam aplikasi tes buta warna, antara lain :

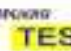

\section{Gambar 13. Halaman Utama}

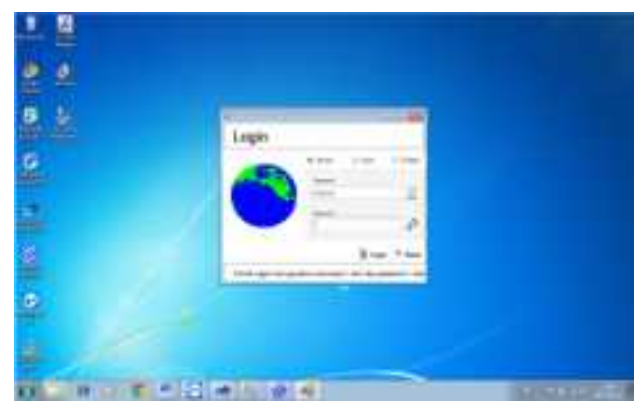

Gambar 14. Halaman Menu Login

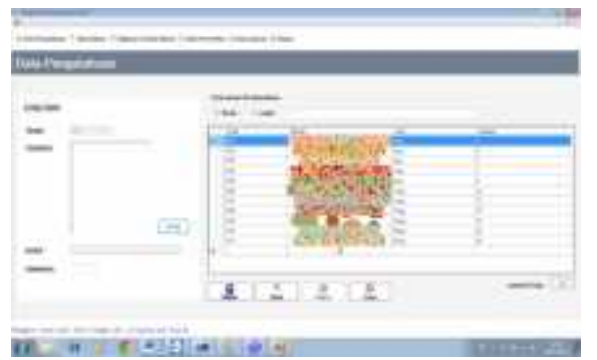

Gambar 15. Tampilan Data Pengetahuan 


\section{KESIMPULAN}

Dari penelitian yang telah dilakukan dapat disimpulkan hasilnya yaitu antara lain :

1. Tes buta warna dilakukan menggunakan buku ishihara yang diimplementasikan kedalam sebuah aplikasi yang dapat menghemat pengeluaran atas kerusakan buku dari waktu kewaktu. Aplikasi ini di bangun dan di rancang menggunakan model pengembangan sistem waterfall dan UML (Unified Modeling Language) dan menggunakan bahasa pemograman Vb.Net10 dengan database SQL Server 2008, sehingga efektif bagi klinik dalam penyimpanan data dan penghematan pengeluaran untuk membeli buku ishihara dan mendapatkan hasil yang akurat.

2. Dalam aplikasi Tes Buta Warna ini terdapat fasilitas untuk penyimpanan hasil tes buta warna dalam sebuah form laporan. Yang dapat membantu mengurangi hilangnya data akibat kertas yang rusak atau hilang, dikarenakan hasil data yang diperoleh disimpan dalam sebuah penyimpanan pada sistem menggunakan database.

3. Aplikasi Tes Buta Warna ini mempunyai fasilitas untuk pemverifikasian data hasil tes buta warna agar tidak terjadinya rekayasa dan juga menjadikan hasil tes buta warna tersebut menjadi lebih akurat dan valid,dengan adanya bukti tanda tangan asli dari dokter yang ahli dalam menangani tes buta warna.

\section{REFERENSI}

[1] Dahlan Abdullah, Irma Oktari. (2015). Aplikasi Perancangan Tes Buta Warna Dengan Menggunakan Metode Ishihara. Jurnal Teknologi Informasi, Vol. 04, No. 1.Universitas Malikussaleh, Aceh.

[2] Dhika ,Randy Viyata. (2014). Aplikasi Tes Buta Warna Dengan Metode Ishihara Pada Smartphone Android. Jurnal Pseudocode, Volume 1 Nomor 1, ISSN 2355 5920.Universitas Bengkulu.

[3] Dr. Hamdan, M.M, dkk. (2015). Pedoman Penulisan Karya IlmiyahUniversitas Serang Raya. UNSERA : Serang.

[4] Hidayatullah Priyanto. (2014). Visual Basic.NET Membuat Aplikasi Database dan Program Kreatif. Bandung : Informatika.

[5] Ishihara, Shinobu, (1994), Ishihara's Tests For Colour Deficiency, 14 Plates Edition, Kanehara \& CO.,LTD, Tokyo-Japan.
[6] Murti, H., Santi, R.C.N. (2011). Aplikasi Pendiagnosa Kebutaan Warna dengan Menggunakan Pemrograman Borland Delphi. Jurnal Teknologi Informasi DINAMIK, Vol. 16, No. 2. ISSN: 0854-9524. Universitas Stikubank , Semarang.

[7] Permana Eka dan Sella Tamara. (2013). Implementasi Sistem Berbasis Web untuk Visualisasi Tes Buta Warna (colourblind test). Jurnal Teknologi Informasi dan Komunikasi, ISSN: 2252-4517. STMIK Subang.

[8] Purnamasari, Prasetya. (2015). Tes Buta Warna Metode Ishihara Berbasis Komputer (Kelas XI Jurusan Teknik Instalasi Tenaga Listrik SMK Negeri 3 Semarang). Teknik Informatika dan Komputer - Jurusan Teknik Elektro, Fakultas Teknik, Universitas Negeri Semarang.

[9] Rini W Benedidicta. (2011). Microsoft Visual Basic 2010 \& MySQL. Yogyakarta: Andi yogyakarta, wahana komputer.

[10] S, Rosa dan Shalahuddin, M. 2014. Rekayasa Perangkat Lunak Terstruktur dan Berorientasi Objek. Bandung: Informatika.Wahana Komputer. 2010. SQL Server 2008 Express. Semarang : Informatika.

[11] Widyastuti M., Suyanto, dkk. (2004). Tes Buta Warna Berbasis Komputer. Seminar Nasional Aplikasi Teknologi Informasi. Yogyakarta.

[12] Widianingsih, R., Kridalaksana, dkk. (2012). Aplikasi Tes Buta Warna dengan Metode Ishihara Berbasis Komputer. Jurnal Informatika Mulawarman, Vol. 5, No. 1. Universitas Mulawarman, Samarinda. 